\title{
PEMANFAATAN CITRA TOPOGRAFI MENGGUNAKAN TRANSFORMASI WATERSHED PADA DAS YANG RAWAN BENCANA ALAM
}

\author{
Image Utilization Topography Using Watershed Transformation In Watersheds Natural Disaster \\ Prone
}

\author{
Muhtar \\ Jurusan Teknik Sipil Fakultas Teknik Universitas Muhammadiyah Jember \\ Alamat Korespondensi : Jl. Karimata 49 Jember \\ Email: Muhtar.fitrah@gmail.com
}

\begin{abstract}
As a country which has abundant natural resources, Indonesia is faced with a problem that arises in the process of exploiting the natural resources, namely the emergence of natural disasters that could potentially cause serious damage in some areas. Threats to flooding and landslides in the watershed (DAS) has been in the spotlight of many researchers in finding the best solution. Utilization topographic image in the field of remote sensing is very useful in the development of disaster management system better. With the support of the use of watershed transformation method , it is possible to obtain data geographical situation, both of dimension flow and slope conditions affecting the water discharge capacity of the watershed. Thus, the risk of natural disasters can be minimized level of material and non-material damage.
\end{abstract}

Keywords : Topography image, Transformation Watershed, Watershed, Natural Disaster Prone

\begin{abstract}
Abstrak
Sebagai Negara yang memiliki sumber daya alam melimpah, Indonesia dihadapkan pada suatu permasalahan yang muncul dalam proses pemanfaatan kekayaan alam itu, yaitu munculnya bencana alam yang berpotensi menyebabkan kerusakan serius dibeberapa daerah. Ancaman terhadap bahaya banjir dan tanah longsor pada daerah aliran sungai (DAS) telah menjadi sorotan banyak peneliti dalam mencari solusi terbaik. Pemanfaatan citra topografi dalam bidang penginderaan jauh sangat bermanfaat dalam pengembangan sistem penanggulangan bencana yang lebih baik. Dengan didukung dengan penggunaan metode transformasi watershed, dimungkinkan memperoleh data situasi geografis, baik dari dimensi aliran maupun kondisi kelerengan yang mempengaruhi kapasitas debit air DAS. Dengan demikian, resiko bencana alam dapat diminimalkan tingkat kerusakan materil maupun non materil.
\end{abstract}

Kata kunci : Citra Topografi, Transformasi Watershed, Daerah Aliran Sungai, Rawan Bencana Alam

\section{PENDAHULUAN}

Perubahan cuaca yang tidak menentu dan ketidakseimbangan ekosistem menjadi salah satu faktor terjadinya bencana alam mengakibatkan kerugian materil dan korban jiwa. Tingginya curah hujan dan perbedaan waktu turunnya intensitas hujan menjadi kendala dalam memprediksi peluang terjadinya debit air yang berlebih pada saluran drainase. Terganggunya keseimbangan lingkungan hidup dari perilaku masyarakat yang kurang baik (membuang sampah sembarangan, memanfaatkan hasil hutan tanpa perhitungan) menjadikan ancaman banjir bisa terjadi kapan saja. Salah satu muara datangnya bahaya ini adalah daerah aliran sungai yang berfungsi sebagai tempat berkumpul dan mengalirnya berbagai macam kiriman air, baik dari perkotaan maupun pegunungan. Bukan hanya banjir, namun bahaya longsor juga mengikuti serentetan bencana alam yang bisa datang saat bersamaan.

Dari fenomena yang ada, aliran air di alam ini memiliki bentuk yang bervariasi disebabkan dari keadaan alam (bentuk permukaan tempat mengalirnya air) dan akibat arah arus yang tidak mudah untuk digambarkan. Aliran sungai yang sedang banjir dan air terjun dari suatu ketinggian tertentu adalah contoh adalah gambaran mengenai bentuk yang sulit dilukiskan secara pasti. Diperlukan pemahaman yang lebih mendalam berkaitan dengan kelerengan disekitar daerah aliran air sebagai 
pencegahan ancaman bahaya bencana alam dengan memanfaatkan teknologi penginderaan jauh menggunakan transformasi watershed.

\section{Daerah Aliran Sungai (DAS)}

Dalam beberapa istilah, DAS disebut juga sebagai catchment area, drainage area, drainage basin, river basin, atau watershed. Di Indonesia, terdapat tiga terminologi sesuai dengan luas dan cakupannya yaitu: Catchment, Watershed dan Basin. Tidak ada batasan baku, tetapi selama ini dipahami bahwa catchmen lebih kecil dari watershed, dan basin adalah DAS besar (Priyono dan Savitri, 2001).

Menurut Dixon dan Easter (1986) DAS adalah suatu area yang dibatasi secara topografis oleh punggung bukit dan air hujan yang jatuh teratuskan oleh suatu sistem sungai. Sedangkan menurut Wiersum (1979), dan Seyhan (1990), DAS adalah suatu wilayah daratan yang dibatasi oleh batas alam berupa topografi yang berfungsi untuk menampung, menyimpan, dan mengalirkan air yang diterima menuju ke sistem sungai terdekat yang selanjutnya bermuara di waduk atau danau atau laut. DAS juga disebut sebagai wilayah yang terletak di suatu titik pada suatu sungai yang oleh batas-batas topografi mengalirkan air yang jatuh di atasnya ke dalam sungai yang sama dan melalui titik yang sama pada sungai tersebut (Brooks et al., 1992; Arsyad, 2010).

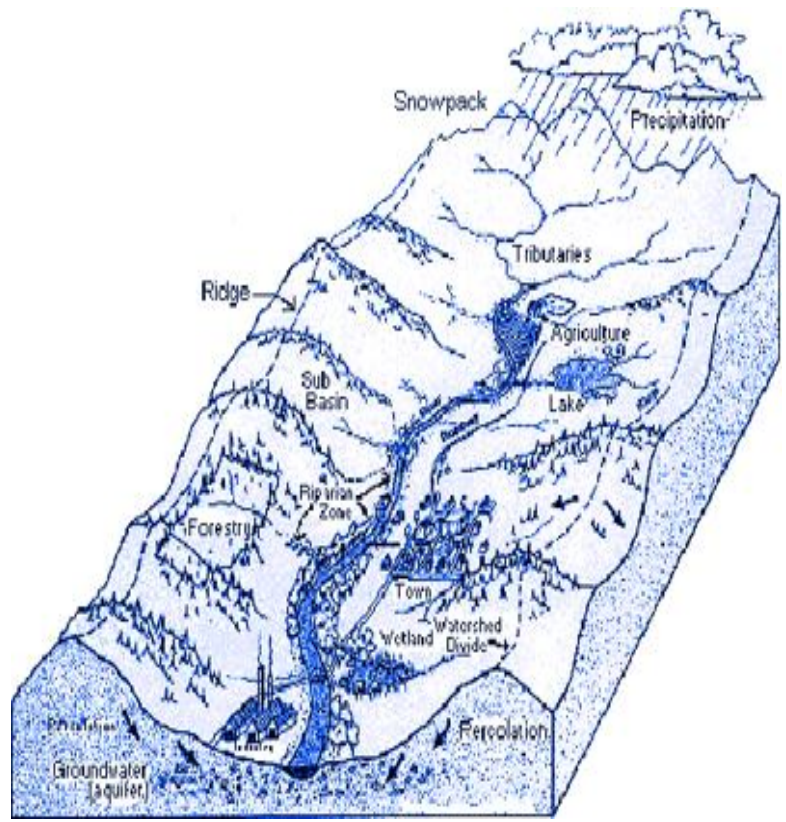

Gambar 1. Siklus Air Pada Daerah Aliran Sungai

(Sumber : www.water.epa.gov/type/watersheds, diakses 07 Januari 2013)

\section{Bencana Alam}

Dalam Undang-Undang No 24 Tahun 2007 tentang Penanggulangan Bencana, disebutkan bencana adalah peristiwa atau rangkaian peristiwa yang mengancam dan mengganggu kehidupan dan penghidupan masyarakat yang disebabkan, baik oleh faktor alam dan/atau faktor non alam maupun faktor manusia sehingga mengakibatkan timbulnya korban jiwa manusia, kerusakan lingkungan, kerugian harta benda, dan dampak psikologis. Sedangkan bencana alam adalah bencana yang diakibatkan oleh peristiwa atau serangkaian peristiwa yang disebabkan oleh alam antara lain berupa gempa bumi, tsunami, gunung meletus, banjir, kekeringan, angin topan, dan tanah longsor. Dalam pengertian yang sama, disebutkan juga rawan bencana sebagai kondisi atau karakteristik geologis, biologis, hidrologis, klimatologis, geografis, sosial, budaya, politik, ekonomi, dan teknologi pada suatu wilayah untuk jangka waktu tertentu yang mengurangi kemampuan mencegah, meredam, mencapai kesiapan, dan mengurangi kemampuan untuk menanggapi dampak buruk bahaya tertentu.

Berikut beberapa bencana alam yang bisa mengancam/terjadi pada daerah aliran sungai, diantaranya :

\section{- Banjir}

Bencana ini diakibatkan curah hujan yang tinggi dan tidak diimbanginya dengan saluran pembuangan air yang memadai, sehingga air yang meluap mampu merendam wilayah-wilayah dengan ketinggian daratan lebih rendah. Pada beberapa kasus penyebab terjadinya banjir karena air danau meluap atau bendungannya jebol, bahkan akibat adanya badai dan gempa bumi. Secara umum, penyebab terjadinya banjir adalah penebangan hutan secara liar tanpa disertai reboisasi, pendangkalan sungai, Pembuangan sampah yang sembarangan, pembuatan saluran air yang tidak memenuhi syarat, pembuatan tanggul yang kurang baik. Dampak negatif yang ditimbulkan bahaya banjir ini yaitu rusaknya areal pemukiman penduduk, sulitnya mendapatkan air bersih, rusaknya sarana dan prasarana penduduk, rusaknya areal pertanian, timbulnya penyakit-penyakit, terhambatnya transportasi darat, dll. 


\section{- Tanah Longsor}

Bencana ini diakibatkan tanah yang turun atau jatuh dari tempat yang tinggi ke tempat yang lebih rendah. Bahaya ini bisa mengancam keamanan pemukiman di atas tanah maupun di bawah tanah yang jatuh, karena material yang jatuh tidak hanya tanah, tetapi juga batu, pohon, pasir, dan lain sebagainya yang bisa menghancurkan apa saja yang ada di bawahnya. Sering juga disebut sebagai kejadian gerakan tanah, tanah longsor merupakan peristiwa geologi yang terjadi karena pergerakan asabatuan atau tanah dengan berbagai tipe dan jenis, seperti jatuhnya bebatuan atau gumpalan besar tanah.

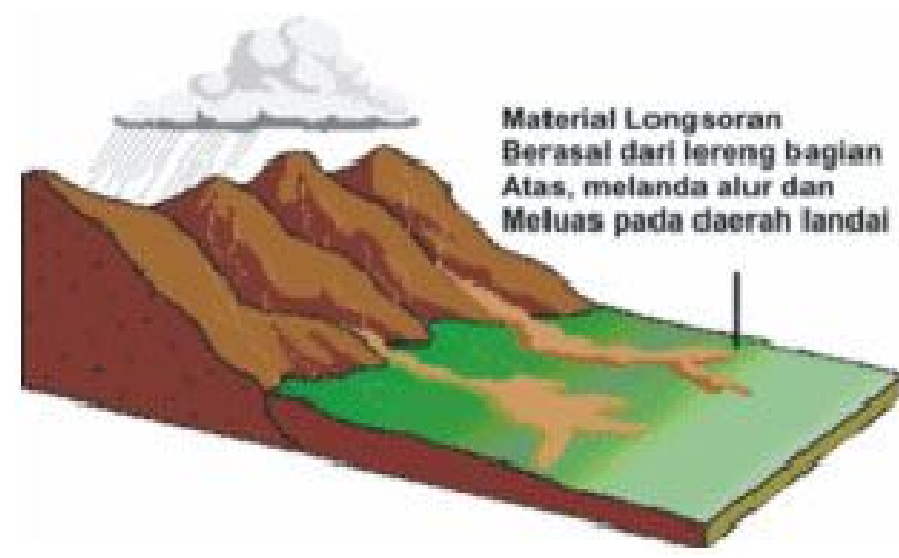

Gambar 2. Skema Tanah Longsor Dataran Tinggi (Sumber : www.museum.bgl.esdm.go.id/, diakses 01 Januari 2011)

Secara umum kejadian longsor disebabkan oleh dua faktor yaitu faktor pendorong (faktor-faktor yang mempengaruhi kondisi material sendiri) dan faktor pemicu (faktor yang menyebabkan bergeraknya material tersebut) (Kementerian ESDM, 2011 ). Meskipun penyebab utama kejadian ini adalah gravitasi yang mempengaruhi suatu lereng yang curam, namun ada pula faktor-faktor lainnya yang turut berpengaruh yaitu erosi yang disebabkan sungai-sungai atau gelombang laut yang menciptakan lereng-lereng yang terlalu curam lereng dari bebatuan dan tanah diperlemah melalui saturasi yang diakibatkan hujan lebat gempa bumi menyebabkan tekanan yang mengakibatkan longsornya lereng-lereng yang lemah gunung berapi menciptakan simpanan debu yang lengang, hujan lebat dan aliran debu-debu getaran dari mesin, lalu lintas, penggunaan bahan-bahan peledak, dan bahkan petir berat yang terlalu berlebihan, misalnya dari berkumpulnya hujan atau salju.

\section{Tranformasi Watershed}

Transformasi ini menganggap gambar sebagai tiga dimensi ( $\mathrm{x}$ dan y merupakan bidang dasar) dengan tingkat warna pixel (gray level) yang dimilikinya dengan ketinggian meningkat dari putih hingga ke hitam. Hal ini menjelaskan bentuk topografi yang beragam titiknya, diantaranya titik yang merupakan minimum regional, titik yang jika air diteteskan akan jatuh ke sebuah posisi minimum tertentu (catchment basin), titik yang jika air titeteskan akan jatuh ke salah satu posisi minimum (garis watershed). Watershed merupakan suatu tool dasar dalam morfologi matematis yang berfungsi untuk segementasi dan sering dimanfaatkan dalam bidang penginderaan jauh untuk mengetahui ketinggian/kontur suatu wilayah.

Tujuan algoritma segmentasi ini didasarkan pada konsep untuk menentukan garis watershed yaitu suatu garis pada permukaan topografi citra. Asumsi dalam transformasi watershed ini dapat digambarkan sebagai bagian/segmen kecil pada topografi citra dianggap sebagai lubang, kemudian menganggap setiap lubang/segmen yang terbentuk dipenuhi air sampai permukaannya sehingga terbentuk semacam basin atau dam yang saling terhubung satu sama lainnya oleh garis batas watershed. Garis watershed adalah garis batas yang menghubungkan tiap-tiap basin atau dam pada topografi citra sehingga terbentuk segmensegmen yang saling terhubung satu sama lainnya.
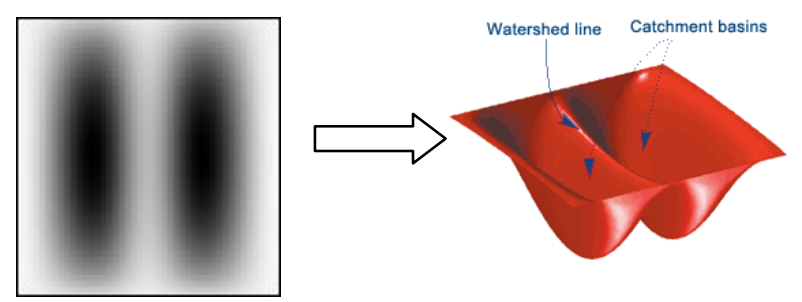

Gambar 3. Gray Level yang Mewakili Areal Basin

(Sumber : www.mathworks.com, diakses 07 Januari 2014)

\section{METODE PENELITIAN}

Dalam kajian ini, citra satelit yang digunakan bersumber dari USGS / The U.S. Geological 
Survey yang memuat informasi tentang air permukaan disuatu daerah, dengan langkah-langkah sebagai berikut :

- $\quad$ Pilih lokasi titik stasiun pengamatan satelit sesuai dengan data yang dibutuhkan.

- Catat koordinat deskripsi stasiun tersebut kemudian unduh berkas DEM 30 meter.

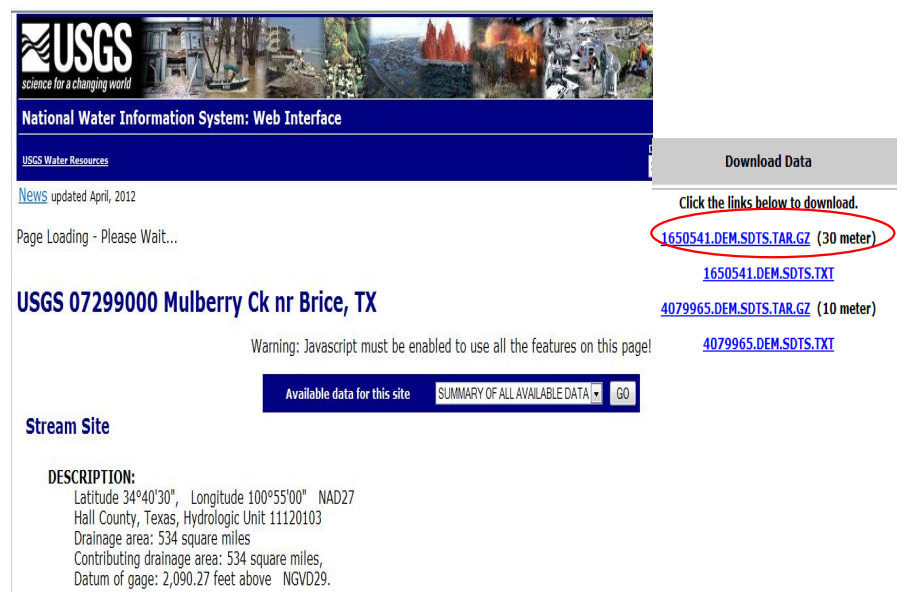

Gambar 4. Berkas DEM 30 meter.

- Berkas yang sudah diunduh selanjutnya diekstrak menggunakan software sdts2dem agar bisa terbaca secara baik pada software Arc GIS. Setelah hasil ekstraksi dikumpulkan dalam satu folder, panggil file DEM yang sudah terkonversi tersebut ke dalam Arc Map dengan merubah kombinasi warna melalui properties yang tersedia. Pilih kombinasi warna yang diinginkan sesuai dengan tujuan klasifikasi ketinggian lereng.

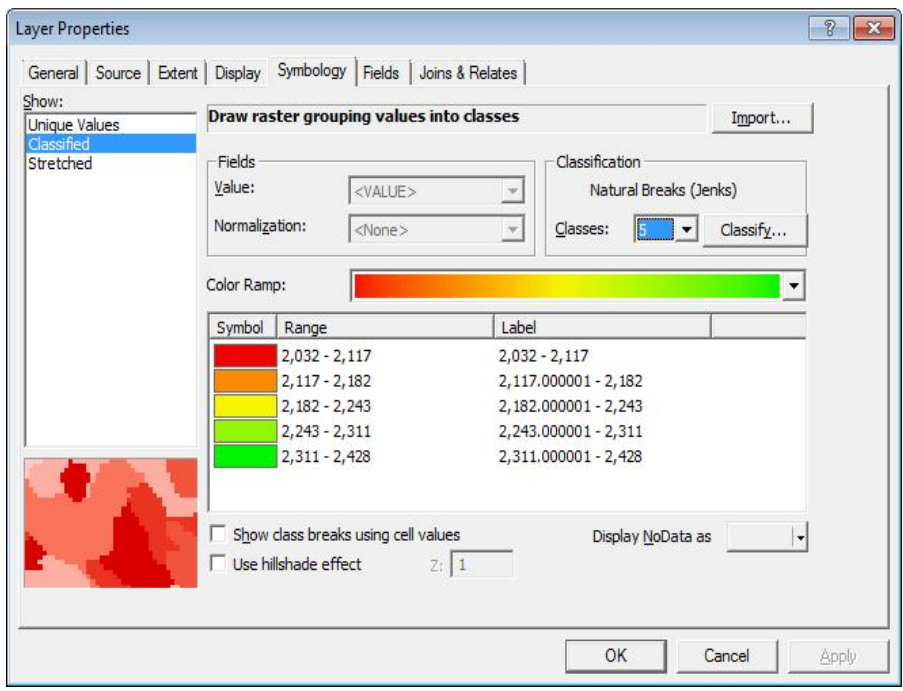

Gambar 5. Software Arc GIS.
- Dari koordinat stasiun yang tercatat, kemudian digunakan untuk merubah transformasi ke dalam sistem UTM dengan zona 14 sesuai dengan lokasi titik stasiun. Selanjutnya melakukan konversi format data DEM ke Raster. Sebagai pelengkap, munculkan permukaannya dengan pilihan Hillshade sehingga tampak topografi yang ditandai dengan derajat keabuan yang berbeda-beda.

\section{HASIL DAN PEMBAHASAN}

Dalam penginderaan jauh, sistem perekaman data dengan menggunakan sensor satelit dapat dibedakan dalam dua bagian yaitu sistem pasif dan sistem aktif. Kedua sistem tersebut sangat berpengaruh terhadap sistem, prosedur,dan metode pengolahan datanya. (Hardiyanti Purwadhi, 2001). Penelitian ini menggunakan citra satelit Landsat 7 Enhanced Thematic Mapper Plus resolusi 30x30 meter multiwaktu sebagai komponen dasar pengambilan data penginderaan jauh sistem pasif (sumber tenaga, atmosfer, interaksi tenaga dengan obyek pada permukaaan bumi, sensor, sistem pengolahan data, dan berbagai penggunaan data). Data satelit Landsat dengan sensornya masingmasing RBV (Return Beam Vidicon), MSS (Multispectral Scanner), dan TM (Thematic Mapper).

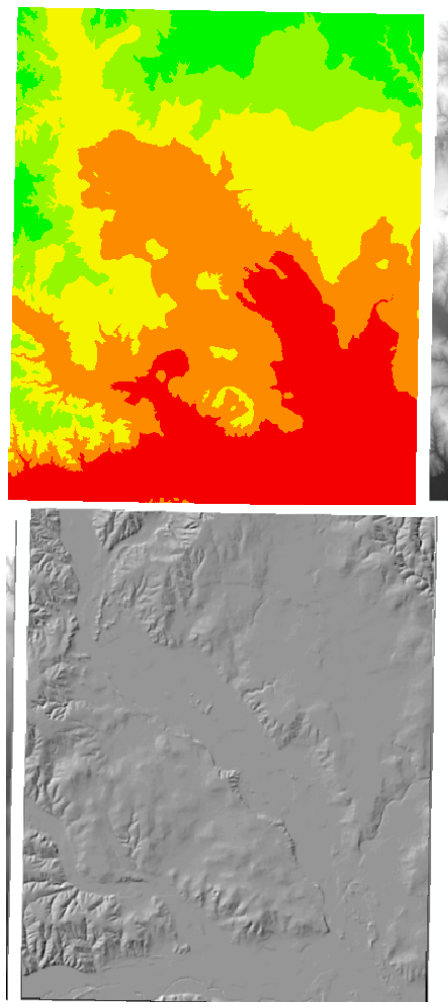

Gambar 5. Hasil

Transformasi

Watershed dengan

Data DEM SRTM

30 meter

(Sumber : Hasil

Penelitian, 2012) 
Dengan menggunakan software pengolah citra (Matlab, Erdas Imagine, ErMapper, Arc-GIS) akan memudahkan citra dalam pre-image processing maupun image processing sehingga mampu meningkatkan kualitas data citra. Pada tahap analisa, citra akan mengeluarkan perbedaan warna yang mengindikasikan beda tinggi pada masingmasing daerah dan akan membentuk kelerengan yang berbeda-beda. Citra satelit yang dirubah menjadi citra skala keabuan akan membentuk suatu area dan setiap perbedaan nilainya akan dijadikan acuan dalam analisa kelerengan wilayah. Citra slope yang dihasilkan akan menunjukkan besar sudut kemiringan sesuai dengan kondisi kontur sebenarnya suatu wilayah.

Dari hasil analisa citra topografi dapat rancang juga beberapa skenario pencegahan dan penanggulangan pada DAS yang rawan bencana, diantaranya dengan mengeruk endapan pada dasar sungai sehingga daya tampung air bisa maksimal; membangun rute drainase alternatif seperti kanalkanal sungai baru dan perpipaan yang dapat mencegah beban debit berlebih pada sungai; memberikan edukasi kepada masyarakat agar tidak mendirikan bangunan pada wilayah penyerapan air dan bibir sungai; tidak menebangi pohon di hutan tanpa reboisasi yang terencana dengan baik karena dapat memicu timbulnya tanah longsor; membuat tembok penahan dan tanggul di sepanjang sungai. Dengan upaya tersebut, diharapkan suatu daerah yang tergolong rawan bencana dengan jumlah penduduk yang besar disekitarnya, akan terminimalkan kerugian materi maupun korban jiwa jika diimbangi dengan ketahanan terhadap bencana yang terencana dengan baik.

\section{KESIMPULAN DAN SARAN}

Pemanfaatan citra topografi sebagai salah satu inovasi dalam penginderaan jauh sangat diperlukan dalam kegiatan pencegahan dan penanggulangan pada DAS rawan bencana, karena data geografis setempat dapat diketahui dengan cepat dan relatif mudah, meskipun daerahnya sulit dijangkau dengan teritris. Upaya terhadap tanggap bahaya bencana alam dapat dilakukan dengan lebih efektif dan aman sehingga bisa mengurangi resiko pada daerah yang memiliki tingkat bahaya dan kerentanan bencana yang tinggi. Hal ini bisa dijadikan evaluasi atas kemampuan sistem dan infrastruktur dalam penanggulangan bencana yang sering terjadi saat ini.

\section{DAFTAR PUSTAKA}

Arsyad, S, 2010, Konservasi Tanah dan Air, IPB Press, Bogor.

Brooks, K. N., P. F. Folliott, H. M. Gregersen, and J.L Thames, 1992, Hydrology and the Management of Watersheds, Iowa State University Press, Ames, USA.

Chang, Kang Tsung, (2010), Introduction to Geographic Information Systems : Fifth Edition, New York.

Martha, Tri KP, dkk, 2012, Aplikasi Citra Satelit DEM (Digital Elevation Model) Dalam Analisa Awal Potensi PLTMH, Seminar Nasional Fisika, Pusat Penelitian Fisika-LIPI, Serpong.

Purwadhi, F. Hardiyanti, Sri, 2001, Interpretasi Citra Digital, Gramedia, Jakarta.

Priyono, C. N. S. dan E. Savitri, 2001, Tinjauan Umum Strategi Konsevasi Tanah dalam Pengelolaan DAS Alami, Jurnal Air, Lahan, Lingkungan dan Mitigasi Bencana, Vol. 8 No.1, Jakarta.

Seyhan, 1990, Dasar-dasar Hidrologi, Yogyakarta: Gadjah Mada University Press.

Sayogo, Singgih Setjo, dkk, 2009, Pemanfaatan Sistem Informasi Geografis Untuk Menganalisis Genangan Air Hujan. Jurnal Neutron, vol.9, no.2, Agustus.

Undang-Undang No 24 Tahun 2007 tentang Penanggulangan Bencana.

Wiersum, K. F, 1979, Introduction to Principles of Forest Hydrology and Erosion, Institute of Ecology, Bandung, Universitas Pajajaran.

Yulianto, S.J.P, Hindriyanto, 2005, Deteksi Perubahan Citra Topografi Pasca Tsunami Aceh Menggunakan Metode Segmentasi Morfologi Watershed. Seminar Nasional Aplikasi Teknologi Informasi, Yogyakarta. http://water.epa.gov/type/watersheds. http://www.mathworks.com. hhtp://nwis.waterdata.usgs.gov/nwis 